\title{
Straddling or overriding tricuspid valve
}

INSERM

\section{Source}

INSERM. (1999). Orphanet: an online rare disease and orphan drug data base. Straddling or overriding tricuspid valve. ORPHA:95461

Straddling or overriding tricuspid valve is a rare, congenital, tricuspid valve malformation characterized by the tricuspid valve that overrides the ventricular septum and communicates with both ventricles, as part of the tension apparatus of the valve crosses the ventricular septal defect and is attached in the left ventricle. The anomaly occurs with other congenital heart defects (transposition of great vessels, left ventricle outflow tract obstruction, double outlet right ventricle, hypoplastic right ventricle), which determine the main clinical manifestation. 